\title{
Beyond quality of life: a cross sectional study on the mental health of patients with chronic kidney disease undergoing dialysis and their caregivers
}

Beatriz dos Santos Pereira', Neimar da Silva Fernandes², Nayara Pires de Melo ${ }^{3}$, Renata Abrita ${ }^{4}$, Fabiane Rossi dos Santos Grincenkov ${ }^{5}$ and Natália Maria da Silva Fernandes ${ }^{6^{*}}$

\begin{abstract}
Background: Patients with terminal chronic kidney disease (CKDT) requiring renal replacement therapies (RRT) undergo important changes in living habits and frequently need caregiving. These patients and their caregivers are risk groups for the development of physical and psychological symptoms. This study aimed to evaluate the prevalence of anxiety, depression, stress, fatigue, social support, and quality of life in patients with CKD and their caregivers.

Method: This cross sectional study was conducted with 21 patients and their caregivers, from January to September 2015. We included patients aged over 18 years, with at least 6 months on dialysis treatment, and caregivers who were family members. The participants' social, demographic, clinical, laboratory, and psychological variables were evaluated. A descriptive analysis and an examination of the association between patients and caregivers were performed.

Results: Among patients, we observed that $38.1 \%$ had symptoms that indicated anxiety and depression. The average score for practical social support was $3.15 \pm 0.769$ and that for emotional social support was $3.16 \pm 0.79$. As for fatigue, $14.3 \%$ of patients reported being 'extremely tired' and $14.3 \%$ reported that they engaged in all the activities they usually performed before the illness. Further, $57.1 \%$ presented stress, and of these, $66.7 \%$ were at the resistance stage, with predominance of psychological symptoms in $60.0 \%$. The quality of life domain in terms of functional capacity (FC) presented a correlation with haemoglobin level $(r=0.581, p=0.006)$ and non-anaemic patients presented better FC. Among caregivers, we observed symptoms that indicated anxiety and depression in $33.3 \%$ of the sample. Caregivers exhibited an average score of $2.88 \pm 0.77$ for practical social support and $3.0 \pm 0.72$ for emotional social support. Further, $14.3 \%$ reported being 'extremely tired' and $28.8 \%$ reported that they engaged in all activities that they usually performed before the patient's illness. When comparing the two groups (patients vs. caregivers), we observed that they presented similar results for the presence of anxiety, depression, and fatigue. Caregivers received less social support than patients did. Both groups presented similar predominance of stress levels; however, patients presented more predominance of psychological symptoms. With reference to quality of life, patients and caregivers presented similar results on the social aspects, vitality, mental health, and mental domains.
\end{abstract}

Conclusion: The mental health characteristics of patients and caregivers were similar, and within the context of dialysis for renal disease, both must undergo specific interventions.

\footnotetext{
* Correspondence: nataliafernandes02@gmail.com

${ }^{6}$ Medical Clinic Department, Federal University of Juiz de Fora (UFJF), Rua Jamil

Altaff, 132, Vale do Ipê, Juiz de Fora, Minas Gerais, Brazil, CEP- 36035380

Full list of author information is available at the end of the article
}

(c) The Author(s). 2017 Open Access This article is distributed under the terms of the Creative Commons Attribution 4.0 International License (http://creativecommons.org/licenses/by/4.0/), which permits unrestricted use, distribution, and reproduction in any medium, provided you give appropriate credit to the original author(s) and the source, provide a link to the Creative Commons license, and indicate if changes were made. The Creative Commons Public Domain Dedication waiver (http://creativecommons.org/publicdomain/zero/1.0/) applies to the data made available in this article, unless otherwise stated. 


\section{Background}

The demographic transition process, characterised by a decrease in mortality and fecundity rates, and population ageing, leads to changes in the country's morbidity standards, with a significant increase in the predominance of chronic non-communicable diseases [1]. Within this context, chronic kidney disease (CKD) appears as a public health problem, because of its predominance, evolution, and financial cost [2].

As a therapeutic resource, CKD relies on conservative treatment (CT); however, when the patient reaches a very low glomerular filtration rate (GFR) (that less than $10 \mathrm{ml} / \mathrm{min} / 1.73 \mathrm{~m}^{2}$ ), there is a need to start renal replacement therapy (RRT) [3, 4]. RRTs constitute the provision of a support system for kidney functions and require important changes in lifestyle that generate the need for patients to adjust their social life, which are also related to the physical limitations resulting from this process [4]. These situations compromises several aspects of the patient's life, such as physical, social, family, and financial, requiring them to adapt to the intense changes caused by the diagnosis and progress of the disease [2]. It renders the patient now dependent on multiple forms of care and on caregivers $[5,6]$.

Within this context, caregivers, mainly family members, represent a risk group for the development of psychological symptoms and several chronic diseases. Therefore, it is essential to evaluate the progress of the experience of becoming sick. However, our reality evidences the lack of and need for studies and interventions that focus on the impact of the disease on patients with CKD and their support group/family [7].

Few studies have addressed the patient-caregiver dyad. For instance, Fan et al. [8] demonstrated that, at the beginning of treatment, patients and caregivers presented similarities in their mental health, with the development and improvement of social function. However, as the disease progressed, caregivers of highly dependent chronic kidney patients (with daily dialysis) presented worsening of their mental health when compared to those of less dependent patients.

Among the psychological consequences found in patients with CKD and their relatives, depression was identified as the most common disorder. According to the studies by Rioux et al. [9] and Arechabala et al. [10], caregivers and patients presented similar mental health conditions, in that both met the criteria for depression as a self-perceived condition, and the symptoms worsened with time.

This situation negatively influences the quality of life of the subject and his/her caregivers, as well as decreases adherence to treatment and increases the rate of clinical complications and mortality [11-13].

The purpose of this study was to evaluate the prevalence of anxiety, stress, depression, and fatigue symptoms, and the levels of quality of life and perceived social support in patients with CKD and their caregivers. Additionally, it aimed to examine the relationship of these variables with patient's clinical characteristics.

\section{Method \\ Study design and period}

This cross sectional study on family caregivers and patients with CKD undergoing RRT [haemodialysis (HD)/ peritoneal dialysis (PD)] was conducted at the hospital of the Federal University of Juiz de Fora (UFJF), from January to September 2015.

This study followed the standards recommended in the Declaration of Helsinki and was approved by the Health Ethics and Research Committee (36345514.1.0000.5139 under number: 081979/2014).

\section{Sample}

Convenience sampling was employed, and 64 participants were approached, of which 30 were patients and 34 were caregivers. Of those, 5 patients did not have caregivers, and, in spite of our initial plan to create a group of patients with no caregivers, this number was very small. Therefore, these patients were excluded from the analysis. Four patients with caregivers who refused to be a part of the survey, and 13 caregivers with patients who refused to participate and did not sign the Free and Informed Consent Terms were excluded. Finally, data from 21 pairs of patients and caregivers were analysed.

Caregivers were considered as the person indicated by patients as 'responsible for taking care of their health at home'.

Inclusion criteria: CKD patients and family caregivers who were older than 18 years of age, from both genders, had been undergoing RRT for at least six months, and who accepted to participate in the survey and signed the Free and Informed Consent Terms were selected for the present study. Exclusion criteria: patients who presented difficulty in understanding the questionnaires or had records of serious cognitive deficits in their medical charts, and those who refused to sign the Free and Informed Consent Terms, were excluded from the sample.

\section{Procedures}

In patients on $\mathrm{HD}$, the survey was conducted during the sessions. For patients treated through PD, the survey was conducted during their medical appointments. In case of caregivers, the interview was performed at the waiting room of the medical clinic, when they visited with their patient.

\section{Variables}

The following social and demographic data of patients and caregivers were evaluated: age, gender, ethnicity, 
level of education, and marital status (according to the Brazilian Institute of Statistical and Geography [IBGE]). Additionally, the following psychological variables were collected using specific instruments: anxiety, depression, perceived social support, fatigue, stress level, and quality of life. For patients, the following additional clinical data were also collected: CKD aetiology, comorbidities, and laboratorial data; haemoglobin $(\mathrm{Hb})$ and haematocrit (HTC) levels; saturation index for transferrin and ferritin; calcium, phosphate, alkaline phosphatase, and parathyroid hormone (PTH) levels; and creatinine, urea, and $\mathrm{Kt} / \mathrm{V}$ levels.

Anxiety and depression were measured using the Hospital Anxiety and Depression Scale (HADS) [14], level of perceived social support through the Scale of Perceived Social Support (SPSS) [15], Fatigue levels through the Fatigue Pictogram [16], stress level and stage through the Lipp's Stress Symptoms Inventory (LSSI) [17], and quality of life through the SF-36 Quality of Life Scale [18] (Table 1).

\section{Statistical analysis}

Qualitative data (gender, fatigue intensity, etc.) were described using frequencies and percentages; quantitative variables (haemoglobin level, age, etc.) were evaluated using mean, standard deviation, minimum, and maximum scores. To correlate the obtained variables for patients and their respective caregivers, the Pearson's and Spearman's correlation coefficients were used and were selected according to the type of variables. To analyse the difference in the central trends of the patient/caregiver pair along the study variables, the Wilcoxon's non-parametric test was used. The significance level was set at $p \leq 0.05$. The statistical software SPSS-17@, Chicago, Illinois was used for all analyses.

\section{Results \\ Patients}

In this study, out of the 21 patients evaluated, 33.3\% were undergoing PD and $66.6 \%$ were undergoing $\mathrm{HD}$. Their age ranged from 29 to 80 years, with an average of $58.9 \pm 14.4$ years. Further, $57.1 \%$ were female, $47.6 \%$ were black, and treatment time varied from seven months to 18 years, with an average of $4.8 \pm 4.7$ years. Additionally, $9.2 \%$ of patients were illiterate and $90.5 \%$ of the patients were not working during the study period. Out of the ones who worked, $50 \%$ had full time jobs. All patients presented high blood pressure, while 33.3\% presented diabetes mellitus. The most prevalent cause of CKD was diabetic nephropathy (33.3\%) and hypertensive nephrosclerosis (23.8\%) (Table 2).

An assessment of the presence of anxiety and depression symptoms showed that $38.1 \%$ presented symptoms indicating anxiety and $38.1 \%$ had symptoms indicating depression (Fig. 1).

On evaluating the perceived social support among the 21 patients, we observed that, for practical support, the minimum score was 1.11 while the maximum score was 3.89 , with an average of $3.15 \pm 0.769$. For emotional

Table 1 Research instruments used in the study

\begin{tabular}{|c|c|c|}
\hline Instrument & Characteristics & $\begin{array}{l}\text { Recommended method of } \\
\text { application }\end{array}$ \\
\hline Social and demographic questionnaire & $\begin{array}{l}\text { This semi-structured interview constituted of questions about the participant's } \\
\text { social and demographic data, and was prepared by the research team. }\end{array}$ & $\begin{array}{l}\text { Non-private instrument from } \\
\text { the psychologist }\end{array}$ \\
\hline $\begin{array}{l}\text { Hospital Anxiety and Depression } \\
\text { Scale (HADS - AD) }\end{array}$ & $\begin{array}{l}\text { It evaluates the presence of anxiety and depression symptoms on a Likert-type } \\
\text { scale with } 14 \text { items [ } 7 \text { for HADS-Anxiety (HADS-A) and } 7 \text { for HADS-Depression } \\
\text { (HADS-D)]. Each item is scored with values from zero to three, constituting a } \\
\text { maximum score of } 21 \text { points for each scale. The cut-off point for the presence } \\
\text { of symptoms is a score of } \geq 9 \text { value. }\end{array}$ & $\begin{array}{l}\text { Non-private instrument from } \\
\text { the psychologist }\end{array}$ \\
\hline $\begin{array}{l}\text { Scale of Perceived Social } \\
\text { Support (SPSS) }\end{array}$ & $\begin{array}{l}\text { This instrument evaluates the social support perceived by the individual. } \\
\text { It comprises } 29 \text { items with answers rated from } 1 \text { to } 4 \text { to evaluate two } \\
\text { dimensions of perceived social support, practical and emotional. }\end{array}$ & $\begin{array}{l}\text { Non-private instrument from } \\
\text { the psychologist }\end{array}$ \\
\hline Fatigue Pictogram & $\begin{array}{l}\text { This illustrated instrument evaluates fatigue. It presents two sets of figures } \\
\text { that evaluate the intensity and impact of fatigue in regular activities. } \\
\text { Figures are presented on an ordinal scale constituted by two questions } \\
\text { with five graduated and captioned illustrations that evaluate the intensity } \\
\text { and impact of fatigue. This tool does not have a cut-off point for the } \\
\text { diagnosis or classification of intensity of fatigue. }\end{array}$ & $\begin{array}{l}\text { Non-private instrument from } \\
\text { the psychologist }\end{array}$ \\
\hline $\begin{array}{l}\text { Lipp's Stress Symptoms } \\
\text { Inventory (LSSI) }\end{array}$ & $\begin{array}{l}\text { This self-report instrument identifies the presence of stress symptoms, } \\
\text { type of existing symptoms (somatic or psychological predominance), } \\
\text { and stage of stress (alarm, resistance, near-exhaustion, and exhaustion). }\end{array}$ & $\begin{array}{l}\text { Private instrument from the } \\
\text { psychologist }\end{array}$ \\
\hline $\begin{array}{l}\text { Quality of Life Questionnaire } \\
\text { (SF-36) }\end{array}$ & $\begin{array}{l}\text { This summarised version of the Medical Outcomes Trust questionnaire } \\
\text { evaluates several quality of life domains by attributing scores (0-100), } \\
\text { with scores closer to zero indicating worse quality of life and those } \\
\text { closer to one hundred indicating better quality of life. }\end{array}$ & $\begin{array}{l}\text { Non-private instrument from } \\
\text { the psychologist }\end{array}$ \\
\hline
\end{tabular}


Table 2 Social and demographic data of patients and caregivers

\begin{tabular}{lll}
\hline & Patients $(n=21)$ & Caregivers $(n=21)$ \\
\hline Age in years (mean, dp) & $58,9 \pm 14,4$ & $47,86 \pm 15,21$ \\
Female (\%) & $12(57,1 \%)$ & $16(76,2 \%)$ \\
Ethnicity (\%) & Black 10 $(47,6 \%)$ & Black 6 (33,3\%) \\
& White 8 (38,1\%) & White 8 (44,4\%) \\
& Mixed Race 3 (14,3\%) & Mixed Race 4 (22,2\%) \\
Marital Status & Married 47.6\% (10) & Married 61.9\% (13) \\
Level of education & $9.2 \%(2)$ of patients were illiterate & $85.7 \%(18)$ had graduated from High School and \\
& Higher education was evidenced for 9.5\% (2) & only 14.3\% (3) graduated from University \\
Place of origin & $28.6 \%(6)$ came from Juiz de Fora & $42.9 \%(9)$ came from Juiz de Fora \\
Work & $90.5 \%(19)$ of patients did not work & $66.7 \%(14)$ had some form of occupational activity \\
Type of Treatment & $14(66.6 \%)$ undergoing HD & - \\
Treatment Time in years & $7(33.3 \%)$ undergoing DP & \\
\hline
\end{tabular}

support, the minimum score was 1.30 and maximum was 4.00, with an average of $3.16 \pm 0.79$ (Fig. 1).

When patients were questioned 'how tired have you felt over this last week?', 14.3\% answered 'extremely tired' and $9.5 \%$ stated that they were 'not tired at all'. However, when asked if this feeling of tiredness prevented them from doing what they wished, $4.8 \%$ reported that 'I can do very little' and $14.3 \%$ said 'I can do everything I normally do' (Fig. 2).

An analysis of the presence of stress symptoms and their level, stage, and symptom type predominance (physical or psychological) showed that, out of 21 patients, $57.1 \%$ presented stress. Of those, $66.7 \%$ were at the resistance stage, $25.0 \%$ were at the near-exhaustion stage, and $8.3 \%$ were at the exhaustion stage. Of the ones diagnosed with stress, $20.0 \%$ presented predominance of physical symptoms, $60.0 \%$ presented predominance of psychological symptoms, and $20.0 \%$ presented both symptoms in equal proportions (Fig. 2).

Based on the amplitude of the laboratory results, we selected a group of variables that can summarise the patient's health conditions related to this study. Thus, we used the $\mathrm{Hb}, \mathrm{Kt} / \mathrm{V}$, and urea levels for further analyses. Several parameters are used to evaluate the adequacy of dialysis. The ones chosen in this study are the most relevant ones. The $\mathrm{Kt} / \mathrm{V}$ level relates to an adequacy rate based on urea depuration. The patients on HD in this study underwent a monthly evaluation. However, there are no specific guidelines for the frequency of evaluation of patients on DP. In our case, it was annual, and $\mathrm{Kt} / \mathrm{V}$ level was not among the variables analysed for patients undergoing RTT in this mode [19]. Therefore, the correlation between laboratory and psychological variables, and treatment time was evaluated (Table 3).

It has been observed that $\mathrm{Hb}, \mathrm{Kt} / \mathrm{V}$ and urea levels did not have a significant correlation with age and with the two questions related to evaluation of fatigue. Further, there were no significant correlations between laboratory exams and both dimensions of perceived social support. Stress evaluation, i.e., presence and predominance of either physical or psychological symptoms, and their stages, were also not correlated to laboratory variables.

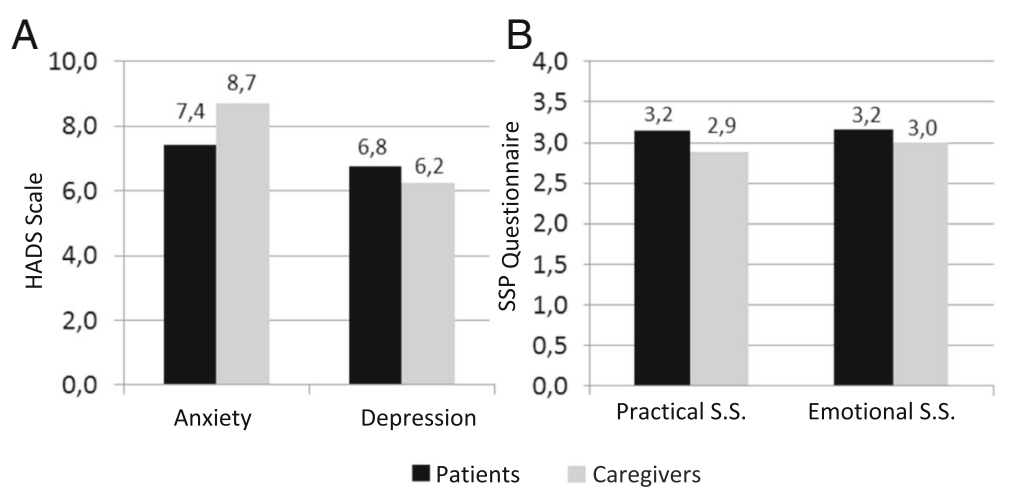

Fig. 1 a -Anxiety and Depression in Patients and Caregivers. b- Social Support in Patients and Caregivers 


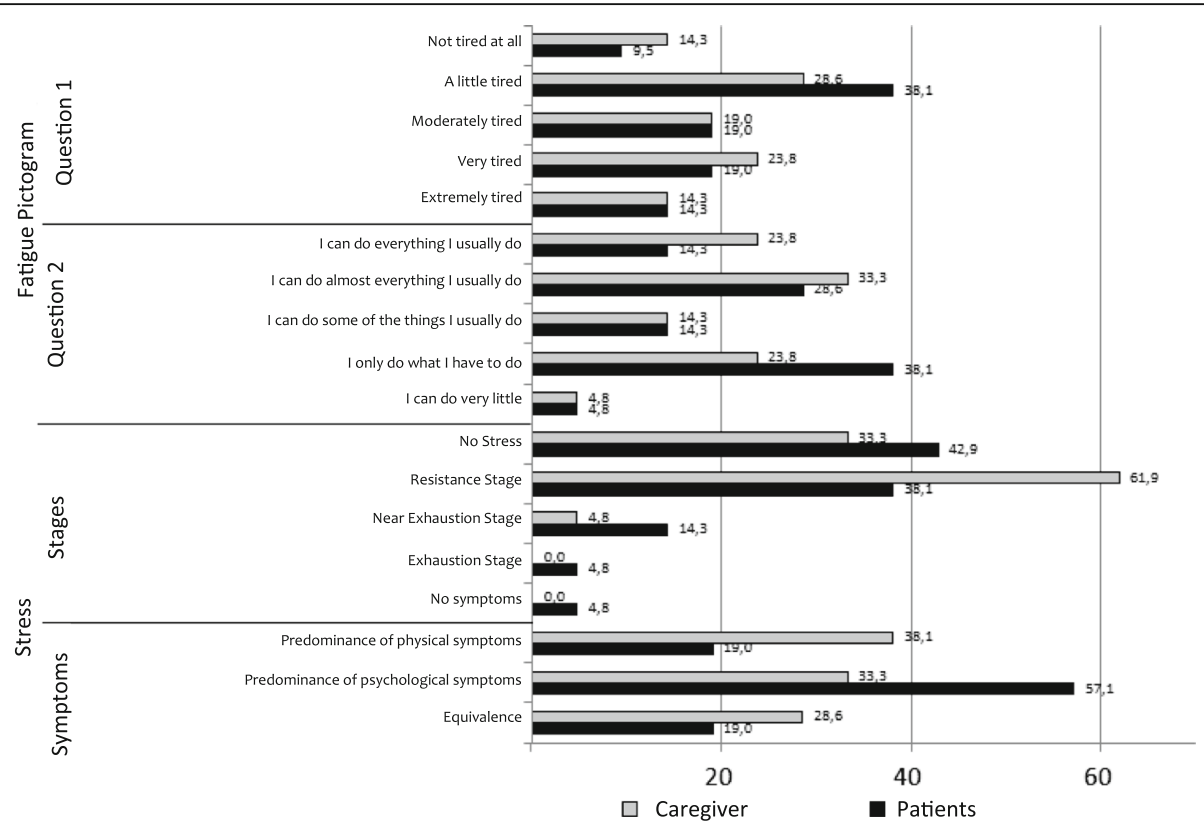

Fig. 2 Fatigue and Stress in Patients and Caregivers

Table 3 Correlation between laboratory and psychological variables and treatment time for patients

\begin{tabular}{|c|c|c|c|c|c|c|c|c|c|}
\hline & \multicolumn{3}{|l|}{ Urea } & \multicolumn{3}{|c|}{ Hemoglobin } & \multicolumn{3}{|l|}{$\mathrm{Kt} / \mathrm{V}$} \\
\hline & $r$ & $p$-value & $n$ & $r$ & $p$-value & $\mathrm{n}$ & $\bar{R}$ & $p$-value & $n$ \\
\hline Functional Capacity ${ }^{a}$ & 0,230 & 0,317 & 21 & 0,581 & 0,006 & 21 & $-0,432$ & 0,123 & 14 \\
\hline Limitation by physical aspects $^{\mathrm{a}}$ & 0,068 & 0,771 & 21 & 0,169 & 0,463 & 21 & $-0,032$ & 0,914 & 14 \\
\hline Pain $^{\mathrm{a}}$ & $-0,019$ & 0,936 & 21 & 0,194 & 0,399 & 21 & 0,103 & 0,727 & 14 \\
\hline General health conditions ${ }^{a}$ & $-0,005$ & 0,982 & 21 & $-0,288$ & 0,206 & 21 & $-0,038$ & 0,899 & 14 \\
\hline Vitality $^{\mathrm{a}}$ & $-0,121$ & 0,602 & 21 & $-0,009$ & 0,970 & 21 & $-0,190$ & 0,515 & 14 \\
\hline Social aspects ${ }^{\mathrm{a}}$ & 0,237 & 0,302 & 21 & 0,173 & 0,454 & 21 & $-0,195$ & 0,503 & 14 \\
\hline Limitation by emotional aspects $^{\mathrm{a}}$ & 0,035 & 0,879 & 21 & 0,184 & 0,425 & 21 & 0,015 & 0,961 & 14 \\
\hline Mental health ${ }^{\mathrm{a}}$ & $-0,105$ & 0,650 & 21 & 0,185 & 0,423 & 21 & $-0,487$ & 0,077 & 14 \\
\hline Physical Domain ${ }^{a}$ & 0,163 & 0,481 & 21 & 0,258 & 0,259 & 21 & $-0,068$ & 0,817 & 14 \\
\hline Mental Domain ${ }^{a}$ & $-0,055$ & 0,812 & 21 & 0,077 & 0,742 & 21 & $-0,276$ & 0,339 & 14 \\
\hline Hospital Anxiety Scale ${ }^{a}$ & $-0,078$ & 0,737 & 21 & $-0,003$ & 0,991 & 21 & 0,166 & 0,571 & 14 \\
\hline Hospital Depression Scale ${ }^{a}$ & $-0,032$ & 0,889 & 21 & $-0,087$ & 0,707 & 21 & 0,288 & 0,318 & 14 \\
\hline Practical Social Support (patient) & 0,321 & 0,156 & 21 & $-0,149$ & 0,519 & 21 & $-0,327$ & 0,253 & 14 \\
\hline Emotional Social Support (patient) & 0,105 & 0,650 & 21 & $-0,214$ & 0,351 & 21 & $-0,222$ & 0,445 & 14 \\
\hline $\begin{array}{l}\text { "How tired have how tired have you felt over this } \\
\text { last week?" (Question } 1 \text { on the Fatigue pictogram) }\end{array}$ & $-0,179$ & 0,437 & 21 & 0,164 & 0,576 & 14 & $-0,028$ & 0,903 & 21 \\
\hline $\begin{array}{l}\text { "How much does the feeling of tiredness prevent } \\
\text { you from doing what you want?" (Question } 2 \text { on } \\
\text { the Fatigue pictogram) }\end{array}$ & 0,136 & 0,558 & 21 & 0,175 & 0,549 & 14 & 0,231 & 0,313 & 21 \\
\hline Stress Stages (According to Lipp) & 0,197 & 0,392 & 21 & 0,099 & 0,669 & 21 & 0,153 & 0,601 & 14 \\
\hline
\end{tabular}

ausing the Spearman Correlation Coefficient

busing the Pearson Correlation Coefficient 
Similarly, the laboratory variables did not have a significant correlation with the presence of anxiety and depression symptoms (Table 3).

On analysing the domains of quality of life, we observed a significant correlation of functional capacity (FC) with $\mathrm{Hb}$ level through the Pearson's correlation coefficient $(r=0.581, p=0.006)$. This indicated that, the better the level of $\mathrm{Hb}$ was, the better was the patient's FC. For illustration purposes, we observed that anaemic patients (8 patients) presented average FC scores of $40.00 \pm 22.20$ and non-anaemic patients (13 patients) had an average score of $61.153 \pm 26.469(p=0.075)$. The same domain did not present a statistically significant result when its correlation with $\mathrm{Kt} / \mathrm{V}(r=-0.432, p=0.123)$ and urea $(r=0.230, p=0.317)$ levels was examined (Table 4$)$.

With reference to the SF-36 domains, only 'limitation from emotional aspects' $(r=0.472 ; p=0.031)$ and 'great mental domain' ( $r=0.370 ; p=0.09)$ presented significant correlations. Anxiety, depression, social support, and stress were not related. Further, no significant relationship was observed between treatment time and fatigue (Table 4).

The most common type of therapy was HD (66.6\%), and there was no difference between HD and PD, probably owing to the size of the sample.

\section{Caregivers}

The study sample included 21 caregivers with the following social and demographic characteristics: age ranged between 26 and 76 years, with an average of $47.86 \pm 15.21$ years; $76.2 \%$ were female; majority of them were married, $61.9 \%$; and $44.4 \%$ were white. Further, $85.7 \%$ had graduated from high school, and $66.7 \%$ were engaged in some sort of occupational activity at the time of the present study (Table 2).

Out of the 21 caregivers, $33.3 \%$ presented symptoms that indicated anxiety and $33.3 \%$ had symptoms that indicated depression (Fig. 1).

The minimum score on perceived practical support was 1.47 and the maximum was 4.00 , with an average of $2.88 \pm 0.77$. As for perceived emotional support, the minimum value was 1.60 and maximum was 4.00 , with an average of $3.00 \pm 0.72$ (Fig. 1).

As for how tired the caregivers were over the last week, approximately $14.3 \%$ reported being 'extremely tired' and $14.3 \%$ reported being 'not tired at all'. When asked about the extent to which their tiredness had limited their activities, $4.8 \%$ stated 'I can do very little' and $23.8 \%$ said, 'I can do everything I normally do' (Fig. 2).

Regarding the presence of stress symptoms, out of the 21 evaluated caregivers, $66.7 \%$ presented stress symptoms. Of those, $92.9 \%$ were at the resistance stage and $7.1 \%$ were at the near-exhaustion stage, while none of the participants was at the alarm or exhaustion stages. Out of the ones diagnosed with stress, $38.1 \%$ presented predominance of physical symptoms, 33.3\% presented predominance of psychological symptoms, and 28.6\% presented both symptoms in equal proportions (Fig. 2).

Scores pertaining to the quality of life, as assessed using the SF-36, have been presented in Fig. 3.

\section{Correlation between patient and caregiver variables}

There was no significant correlation between the patients' and caregivers' age $(r=0.269, p=0.238)$.

When evaluating the presence of anxiety and depression symptoms, we observed that patients and caregivers

Table 4 Correlation between quality of life in patients and caregivers

\begin{tabular}{|c|c|c|c|c|c|c|c|c|}
\hline \multirow[b]{2}{*}{ Variables } & \multicolumn{2}{|l|}{ Patient } & \multicolumn{4}{|c|}{ Caregiver } & \multicolumn{2}{|c|}{ Correlations } \\
\hline & Average & Standard deviation & Average & Standard deviation & Z & $\overline{p \text {-value }}$ & $r$ & $p$-value \\
\hline Functional Capacity & 53,09 & 26,52 & 74,52 & 26,64 & $-2,61$ & 0,014 & 0,191 & 0,406 \\
\hline Pain & 48,66 & 30,44 & 56,95 & 24,93 & $-0,96$ & 0,344 & $-0,223$ & 0,331 \\
\hline General health conditions & 51,00 & 26,85 & 63,47 & 26,75 & $-1,51$ & 0,179 & $-0,084$ & 0,717 \\
\hline Vitality & 58,81 & 28,37 & 44,52 & 27,29 & 1,66 & 0,198 & $-0,312$ & 0,168 \\
\hline Social aspects & 60,71 & 32,42 & 63,69 & 32,33 & $-0,30$ & 0,913 & 0,360 & 0,109 \\
\hline Mental health & 66,48 & 25,19 & 57,33 & 24,11 & 1,20 & 0,321 & $-0,079$ & 0,732 \\
\hline Physical aspects & 33,33 & 36,51 & 64,28 & 38,38 & $-2,68$ & 0,006 & 0,334 & 0,138 \\
\hline Emotional aspects & 41,26 & 40,69 & 55,55 & 45,13 & $-1,08$ & 0,103 & 0,625 & 0,002 \\
\hline Physical Domain & 36,36 & 8,96 & 46,29 & 10,29 & $-3,33$ & 0,005 & $-0,021$ & 0,929 \\
\hline Mental Domain & 45,65 & 12,07 & 40,09 & 15,01 & 1,32 & 0,170 & 0,176 & 0,447 \\
\hline Anxiety & 7,42 & 5,35 & 8,71 & 3,84 & $-0,928$ & 0,37 & 0,077 & 0,741 \\
\hline Depression & 6,76 & 4,79 & 6,23 & 4,41 & 0,419 & 0,71 & 0,227 & 0,322 \\
\hline Practical Social Support & 3,15 & 0,76 & 2,88 & 0,77 & 1,309 & 0,27 & 0,278 & 0,222 \\
\hline Emotional Social Support & 3,16 & 0,79 & 3,00 & 0,72 & 0,993 & 0,50 & 0,548 & 0,010 \\
\hline
\end{tabular}


Functional Capacity

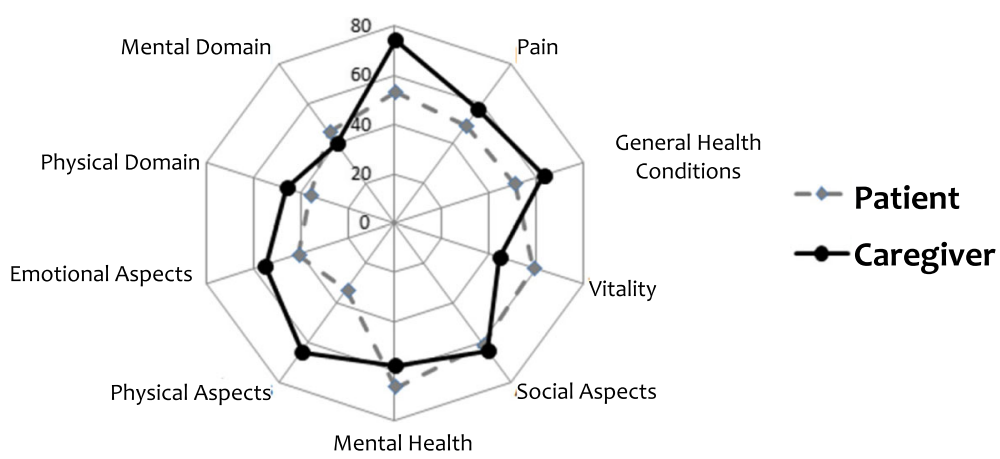

Fig. 3 Quality of Life in Patients and Caregivers

presented very similar averages for both symptoms (Fig. 1) and there was no significant correlation (Pearson's correlation coefficient) between the patients' and caregivers' results. In the analysis to examine differences in anxiety and depression using the Wilcoxon test, no significant differences were observed for anxiety, with patients presenting an average of $7.43 \pm 5.35$ and caregivers an average of $8.71 \pm 3.85 \quad(\mathrm{z}=-0.802, \quad p=0.423)$. Similar findings were observed for depression, with patients presenting an average of $6.76 \pm 4.79$ and caregivers an average of $6.24 \pm 4.41(\mathrm{z}=-0.423, p=0.672)$.

On comparing the perceived social support between patients and caregivers, again, very similar values were observed. However, even with close values, we observed that caregivers presented smaller averages than patients did, indicating that caregivers received less social support, either practical or emotional (Fig. 1). There was no significant correlation between the practical social support scores of patients and caregivers; however, there was significant correlation between their emotional social support scores $(r=0.548, p=0.010)$.

In another statistical approach, the perceived social support was examined with reference to practical and emotional aspects; however, no statistical significant findings were observed. For practical social support, patients presented an average of $3.15 \pm 0.77$ and caregivers an average of $2.89 \pm 0.78(\mathrm{z}=-1.165, p=0.244)$, as for emotional social support, patients presented an average of $3.17 \pm 0.80$ and caregivers an average of $3.01 \pm$ $0.72(\mathrm{z}=-1.121, p=0.262)$.

When evaluating fatigue levels and their interference in daily activities, when asked 'How tired have you felt over this last week?', patients and caregivers presented similar percentages distribution of fatigue levels $(p=0.89)$. The same was observed with reference to the patients' and caregivers' responses to 'To what extent does the feeling of tiredness prevent you from doing what you want?' $(p=0.30)$. There were no significant correlations between patients' and caregivers' responses for either of these questions $(r=-0.215, \quad p=0.349 ; \quad r=-0.045, \quad p=0.847$, respectively).

Excluding the cases of absence of stress, on examining the predominance of physical/psychological symptoms/ both in the patients and their caregivers, we observed that patients tended to present more psychological stress symptoms $(75 \%, 16)$ when compared to caregivers $(46.7 \%, 15)$. However, this result did not reach statistical significance $(p=0.149)$. However, there were no differences between patients and caregivers in terms of the presence of stress ( $p=0.751)$ (Fig. 2).

Regarding stress stages, both groups presented similar results $(p=0.967)$. There was no difference between the groups for the incidence of physical symptoms $(p=0.640)$. However, patients tended to be more psychologically stressed than caregivers did, though the observed difference was not statistically significant $(p=0.071)$. For predominance of physical or psychological symptoms, including patients with no stress symptoms and cases that showed both symptoms equally, no significant difference was observed $(p=0.220)$.

There was no significant correlation between the presence and stages of stress $(r=0.070, p=0.764)$, i.e., the intensity of patient stress was not related to the intensity of caregiver stress. On evaluation of the predominance of physical or psychological symptoms, the Chi-square test presented no relationship between the categories $\left(X^{2}=2.213, p=0.137\right)$ indicating that the predominance of a certain symptom in patients is not related to any physical/psychological characteristic of the caregiver.

With reference to the SF-36 scores, we observed statistically significant differences in that patients presented less FC in relation to caregivers, with patients achieving an average of $53.092 \pm 26.527$ and caregivers an average of $74.523 \pm 26.641(z=-2.453, p=0.014)$. Patients exhibited more limitations due to physical aspects, and they presented an average of $33.33 \pm 36.51$, while caregivers presented an average of $64.28 \pm 38.38(z=-2.72, p=0.006)$. As for the 'physical' domain, we observed that patients 
presented lower scores, with an average of $36.36 \pm 8.96$, while caregivers obtained an average of $46.29 \pm 10.29$ $(z=-2.833, p=0.005)$ (Fig. 3).

We observed that, for the physical domain, caregivers presented values that indicated higher quality of life pertaining to this aspect (Fig. 3).

Other clinically relevant findings were related to the sub-domains of vitality, social aspects, mental health, and the larger mental domain, with patients and caregivers presenting similar scores. In these categories, we also observed a tendency of caregivers to obtain lower scores, indicating comparatively worse quality of life in these aspects as compared to patients (Fig. 3).

Further, there was significant correlation in the scores on limitation by emotional aspects between patients and caregivers $(r=0.625, p=0.002)$.

Even though some results did not reach statistical significance, the following findings are notable: in the 'general health conditions' domain, we observed an average of $51.00 \pm 26.85$ for patients and $63.47 \pm 26.75$ for caregivers, which demonstrates that patients presented lower scores $(z=-1.345, p=0.179)$, and for vitality, patients presented an average of $58.81 \pm 28.37$ and caregivers an average of $44.52 \pm 27.29$, which demonstrates that caregivers presented lower scores $(z=-1.345, p=0.179)$. Further, for limitation by emotional aspects, patients presented an average of $41.27 \pm 40.69$ and caregivers an average of $55.55 \pm 45.13$, where lower patient scores are evident $(z=-1.628, p=0.103)$, and for the mental domain, patients presented an average of $45.66 \pm 12.07$ and caregivers presented an average of $40.09 \pm 15.10$, which demonstrates that caregivers had lower scores on the mental domain, and lower quality of life in this aspect $(z=1.373$, $p=0.170)$. Under the domains of pain $(z=-0.947, p=$ $0.344)$, social aspects $(\mathrm{z}=-0.110, p=0.913)$ and mental health $(\mathrm{z}=-0.992, p=0.321)$ there were no significant differences (Fig. 3).

\section{Discussion}

In this study, we observed that the prevalence of anxiety, depression, perceived social support, fatigue, stress symptoms, and levels of quality of life in patients with CKD and their caregivers was similar, and some variables presented worse scores in caregivers. Additionally, we evaluated the relationship of psychological variables between patients and caregivers, and found that some of them were related.

A recent study by Urquhart-Secord $\mathrm{R}$ et al., with 83 patients undergoing HD and their caregivers in Australia and Canada, evaluated 68 questions on outcomes in dialysis. They considered mortality, anxiety, and depression as the most relevant variables, as do most studies performed with this population [20].
In our study, the prevalence of anxiety and depression was similar to that reported in the literature. For instance, Arechabala et al. evaluated the presence of depression symptoms and their correlation to perceived social support and fatigue level with 162 pairs of patients and caregivers. It was observed that both groups presented similar levels of depression symptoms [10].

Social support, both practical and emotional, is vital for chronically ill patients and their caregivers. Our results showed that caregivers presented lower averages than patients did, even though there was no statistical significance. The correlation of emotional support between the two groups shows that patients who have more emotional social support tend to be cared for by caregivers who also have more social support in this aspect. This data reinforces the notion that other psychological variables, such as anxiety and depression, must be observed in caregivers to promote their mental health and their ability to provide support to patients. This result corroborates with those of studies conducted by Schwartz et al., which evidence the importance of the development of a support network to face CKD. It is recommended that this network constitute other family members, neighbours, and friends, and that it should incorporate the influence of spirituality on each individual, and the bond with healthcare professionals, to promote adhesion to treatment and to support patients to fight the disease [21].

Regarding fatigue, our study obtained similar results for patients and caregivers in relation to the level of fatigue and interference of fatigue in daily activities. In a study on the presence of fatigue in patients with kidney disease and their caregivers, Schneider highlighted that fatigue can be an important early symptom that indicates decrease in caregiver quality of life. Additionally, the physical and psychological conditions of this group, which are often neglected, may be important for the adjustment and recovery of patients with CKD [22].

When evaluating the stress presented by patients and caregivers in our study, we found similar results with reference to the presence of stress symptoms and stages. Patients also had the tendency to present more psychological symptoms than caregivers did. In a systematic review, in 2014, Garcia-Llana evaluated 38 studies on chronic diseases and found that only two of them had evaluated stress. These studies evaluated the impact of stress on quality of life, and both studies concluded that stress, mental, and physical health, evaluated together with quality of life, are indirectly related [23].

Quality of life in caregivers of chronic patients can be changed as a result of the caring process and also by the worsening of the disease. Pinto et al. evaluated quality of life in caregivers of patients with Alzheimer's, using information from 118 participants. It was observed that the most compromised scores on the SF-36 were related to 
vitality, and physical and emotional aspects. Worse quality of life in caregivers was related to worse FC in patients, and it was found to have a negative impact on the care provided [24]. Similarly, in our study, when comparing patients and caregivers, patients presented lower scores on the physical domain, and for pain, the results were similar. Caregivers presented even lower levels of vitality and mental health. Results also demonstrated that patients who are more emotionally limited tend to be cared for by caregivers who are also more limited in this aspect.

Shiue and Sand [25] suggest that proper training and support for caregivers is necessary to decrease care overload. To demonstrate this, a population-based study was performed to evaluate quality of life in caregivers with and without previous chronic diseases. It was observed that caregivers with current chronic diseases (1.562) presented physical health limitations, body pains, and emotional problems, and they were less active. Caregivers with no chronic diseases (1.151) presented similar results [25]. In our study, caregivers presented lower quality of life in the domains of vitality and mental health.

Caregivers of patients undergoing dialysis also experience adverse effects to their quality of life, and therefore, interventions for educational, social, and psychological support are essential to promote their ability to handle adversities generated by this context, as highlighted by Celik et al. When comparing quality of life of 142 pairs of patients undergoing dialysis and their caregivers, and their symptoms of anxiety and depression, and quality of sleep, it was observed that both groups presented similar results for the physical and mental components of quality of life, and caregivers presented having more problems related to sleep [26].

Owing to the importance of family relationships to promote/generate risk health behaviours and the response of the patient to the disease, the biopsychosocial support model, that is widely used currently, intends to attend to and comprehensively intervene with individuals and their social environment, especially their family unit. These interventions intend to promote strategies to establish healthier and more organized families and communities to prevent the worsening of health and to help patients face adversities [27].

Our study has some limitations, information about the duration for which the caregivers had been playing this role was not obtained.

We concluded that patients and caregivers presented similar mental health levels and, interventions that consider both groups together and individually must be implemented.

\section{Conclusions}

Support groups are well recommended for this population because such groups would help us cater to both patients and caregivers simultaneously, to help them adapt more easily to the RRT routine. Group treatment, in this situation, allows for greater acceptance and identification among the members, promoting benefits to physical and mental health. Additionally, studies using this approach are recommended.

\section{Abbreviations \\ CKD: Chronic kidney disease; CKDT: Terminal chronic kidney disease; $C T$ : Conservative treatment; GFR: Glomerular filtration rate; HADS-AD: Hospital anxiety and depression scale; $\mathrm{Hb}$ : Haemoglobin; HTC: Haematocrit; IBGE: Brazilian Institute of Statistical and Geography; Kt/N: This variable relates to an adequacy rate based on urea depuration; PTH: Parathyroid hormone; LSSI: Lipp's stress symptoms inventory; RRT: Renal replacement therapies; Sf-36: Quality of life questionnaire; SPSS: Scale of perceived social support \\ Acknowledgement \\ IMEPEN Foundation (Interdisciplinary Nucleous of Research in Nephrology). \\ Funding \\ Source(s) of funding for all authors: This study was conducted using own funding. This study followed the standards recommended in the Declaration of Helsinki and was approved by the Health Ethics and Research Committee of the Hospital Universitário da Universidade Federal de Juiz de For a- Minas Gerais, Brasil, under number: 081979/2014.}

Availability of data and materials

Data are available for evaluation.

\section{Authors' contributions}

BdosSP: Bachelor in Psychology, Federal University of Juiz de Fora (UFJF) Interdisciplinary Nuclei of Nephrology Studies and Researches (NIEPEN); contribution to the study: idea development, planning and supervision of data collection, data analysis and interpretation, results discussion and interpretation, and revision and approval of the final version of the paper. NdSF: Bachelor in Exact Sciences, Federal University of Juiz de Fora (UFJF); contribution to the study: data analysis and interpretation, results discussion and interpretation, and revision and approval of the final version of the paper. NPdeM: Bachelor in Social Services, Federal University of Juiz de Fora (UFJF); contribution to the study: data collection. RA Bachelor in Psychology, Higher Education Center of Juiz de Fora (CES); contribution to the study: data collection. FRdosSG: PhD, Professor at the Psychology University, Federal University of Juiz de Fora (UFJF); contribution to the study: idea development, and revision and approval of the final version of the paper. NMdaSF: MD, PhD, Professor at the Medicine University, Medical Clinic Department, Federal University of Juiz de Fora (UFJF); contribution to the study: idea development, planning and supervision of data collection, data analysis and interpretation, results discussion and interpretation, and revision and approval of the final version of the paper.

\section{Competing interests}

The authors declare that they have no competing interests.

\section{Consent for publication}

Not applicable.

\section{Ethics approval and consent to participate}

This study followed the standards recommended in the Declaration of Helsinki and was approved by the Universidade Federal de Juiz de Fora, Health Ethics and Research Committee (36345514.1.0000.5139 under number: 081979/2014). The informed consent was obtained for all participants.

\section{Publisher's Note}

Springer Nature remains neutral with regard to jurisdictional claims in published maps and institutional affiliations.

\section{Author details}

${ }^{1}$ Psychology, Federal University of Juiz de Fora (UFJF) - Interdisciplinary Nuclei of Nephrology Studies and Researches (NIEPEN), Juiz de Fora, Brazil. 
${ }^{2}$ Exact Sciences, Federal University of Juiz de Fora (UFJF), Juiz de Fora, Brazil. ${ }^{3}$ Social Services, Federal University of Juiz de Fora (UFJF), Juiz de Fora, Brazil. ${ }^{4}$ Psychology, Higher Education Center of Juiz de Fora (CES), Juiz de Fora, Brazil. ${ }^{5}$ Psychology University, Federal University of Juiz de Fora (UFJF), Juiz de Fora, Brazil. ${ }^{6}$ Medical Clinic Department, Federal University of Juiz de Fora (UFJF), Rua Jamil Altaff, 132, Vale do Ipê, Juiz de Fora, Minas Gerais, Brazil, CEP36035380

Received: 31 May 2016 Accepted: 30 March 2017

Published online: 17 April 2017

\section{References}

1. Paim J, et al. O sistema de saúde brasileiro: história, avanços e desafios. Lancet. 2011. doi:10.1016/S0140-6736(11)60054-8.

2. Fráguas $G$, Soares SM, Silva PAB. A família no contexto do cuidado ao portador de nefropatia diabética: demandas e recursos. Esc Anna Revista de Enfermagem. 2008;12(2):271-7.

3. Bastos MG, Kirstajn GM. Chronic kidney disease: importance of early diagnosis, immediate referral and structured interdisciplinary approach to improve outcomes in patients not yet on dialysis. J Bras Nefrol. 2011;33(1):93-108.

4. Thomas CV, Alchieri JC. Qualidade de vida, depressão e características de personalidades em pacientes submetidos à hemodiálise. Avaliação Psicológica. 2005;4(1):57-64.

5. Rodrigues TA, Botti NCL. Providing and receiving nursing care during hemodialysis. Acta Paul de Enfermagem. 2009;22:528-30.

6. Dyniewicz AM, Zanella E, Kobus LSG. Narrativa de uma cliente com insuficiência renal crônica: a história oral como estratégia de pesquisa. Revista Eletrônica de Enfermagem. 2004;06(02):199-212.

7. Brito DCS. Cuidando de quem cuida: estudos de caso sobre o cuidador principal de um portador de insuficiência renal crônica. Psicologia em Estudo Maringá. 2009;14(3):603-7.

8. Fan SL, et al. Quality of life of careguivers and patients on peritoneal dialysis. Nephrol Dial Transplant. 2008;23(5):1713-9.

9. Rioux JP, Narayanan R, Chan CT. Caregiver burden among nocturnal home hemodialysis patients. Hemodial Int. 2012;16(2):214-9.

10. Arechabala MC, et al. Depression and self-perceived burden of care by hemodialysis patients and their caregivers. Rev Panam Salud Publica. 2011;30(1):74-9.

11. Almeida A, Meleiro M, Alexandrina MAS. Revisão: Depressão e Insuficiência Renal Crônica: uma revisão. Jornal Brasileiro de Nefrologia. 2000;22(1):192-200.

12. Almeida AM. Revisão: a importância da saúde mental na qualidade de vida e sobrevida do portador de insuficiência renal crônica. J Bras Nefrol. 2003; 25(4):209-14.

13. Saeed Z, et al. Depression in patients on hemodialysis and their caregivers Saudi J Kidney Dis Transpl. 2012;23(5):946-52.

14. Marcolino JAM, Mathias LAST, Piccininl L, Guaratini AA, Suzuki FM, Alli LAC. Escala Hospitalar de Ansiedade e Depressão: Estudo da Validade de Critério e da Confiabilidade com Pacientes no Pré-Operatório. Rev Bras Anestesiol. 2007;57(1):52-62

15. Siqueira MMM. Construção e validação da Escala de Percepção de Suporte Social. Psicologia em Estudo. 2008;13(2):381-8 Maringá.

16. Mota DDCF, Pimenta CAM, Fich MI. Pictograma de Fadiga: uma alternativa para avaliação da intensidade e impacto da fadiga. Rev Esc Enferm USP. 2009;43(Esp):1080-7.

17. Lipp MEN. Manual do Inventário de Sintomas de Estresse para Adultos de Lipp (ISSL). São Paulo: Casa do Psicólogo; 2014

18. Cicconelli RM. Tradução para o português e validação do questionário genérico de avaliação de qualidade de vida "Medical Outcomes Study 36item-short-form health survey (SF-36)". 1997. 143 f. São Paulo: Tese (Doutorado em Medicina) - Escola Paulista de Medicina, Universidade Federal de São Paulo; 1997.

19. NKF KDOQI Guidelines - National Kidney Foundation. 2006. Available at: http://www2.kidney.org/professionals/KDOQI/guideline_upHD_PD_VA/, Accessed on 2 Jan 2016

20. Urquhart-Secord R et al. Patient and caregiver priorities for outcomes in hemodialysis: an international nominal group technique study. Am J Kidney Disease. 2016;68(3):444-54. doi:10.1053/j.ajkd.2016.02.037.

21. Schwartz $\mathrm{E}$, et al. As redes de apoio no enfrentamento da doença renal crônica. Revista Mineira de Enfermagem. 2009;13(2):183-92.

22. Schneider RA. Fatigue among caregivers of chronic renal failure patients: a principal components analysis. Nephrol Nurs J. 2003;30(6):629. -633-664.
23. García-Llana $H$, et al. The role of depression, anxiety, stress and adherence to treatment in dialysis patients' health-related quality of life: a systematic review of the literature. Nefrologia. 2014;34:637-57.

24. Pinto MF, Barbosa DA, Ferreti CEL, Souza LF, Farm DS, Belasco AGS. Qualidade de vida de cuidadores de idosos com doença de Alzheimer. Acta Paul Enferm. 2009:22(5):652-7.

25. Shiue I, SM. Quality of life in caregivers with and without chronic disease: Welsh Health Survey, 2013. J Public Health (Oxf). 2016;39(1):34-44. doi:10. 1093/pubmed/fdv210

26. Celik $\mathrm{G}$, et al. Are sleep and quality of life of family caregivers affected as much as those of hemodialysis patients? Gen Hosp Psychiatry. 2012:34(5):518-24.

27. Straub R. Permanecendo saudável: prevenção primária e psicologia positiva. In: Psicologia da Saúde: uma abordagem biopsicossocial. Porto Alegre: Artmed; 2014. p. 144-77.

\section{Submit your next manuscript to BioMed Central and we will help you at every step:}

- We accept pre-submission inquiries

- Our selector tool helps you to find the most relevant journal

- We provide round the clock customer support

- Convenient online submission

- Thorough peer review

- Inclusion in PubMed and all major indexing services

- Maximum visibility for your research

Submit your manuscript at www.biomedcentral.com/submit
Biomed Central 